Joyful Learning Journal

\title{
APEL PENGUATAN PENDIDIKAN KARAKTER BENTUK PENANAMAN SIKAP TANGGUNG JAWAB SISWA SD
}

\section{Eva Triyani ${ }^{\bowtie}$, A Busyairi $H$}

Jurusan Pendidikan Guru Sekolah Dasar, Fakultas Ilmu Pendidikan, Universitas Negeri Semarang, Indonesia

\begin{tabular}{l}
\hline Info Artikel \\
\hline Sejarah Artikel: \\
Diterima Januari \\
$\mathbf{2 0 2 0}$ \\
Disetujui Februari \\
$\mathbf{2 0 2 0}$ \\
Dipublikasikan Maret \\
$\mathbf{2 0 2 0}$ \\
\\
\hline Keywords: \\
Morning roll call of \\
strengthening the character \\
education; responsibility; \\
strengthening the character \\
education
\end{tabular}

\begin{abstract}
Abstrak
Tujuan penelitian ini adalah mendeskripsikan penanaman sikap tanggung jawab siswa kelas 3A SDN Tambakaji 01 melalui apel penguatan pendidikan karakter. Penelitian ini menggunakan metode deskriptif kualitatif. Pengumpulan data menggunakan teknik observasi, catatan lapangan, wawancara, angket, dan dokumentasi. Teknik analisis data dilakukan dengan uji keabsahan menggunakan triangulasi sumber, triangulasi teknik, dan triangulasi waktu. Kemudian melakukan uji konfirmabilitas. Hasil penelitian ini menunjukkan bahwa: (1) apel penguatan pendidikan karakter memiliki tiga kegiatan yang dijadikan sebagai sarana penanaman sikap tanggung jawab syakni pembiasaan, pemberian teladan, serta penguatan; (2) Hambatan pelaksanaan apel penguatan pendidikan karakter meliputi faktor cuaca yang kurang mendukung, letak kelas yang jauh dari lapangan, kurangnya bimbingan dan arahan guru kelas 3A serta rasa malas siswa kelas 3A; (3) Siswa kelas 3A memberikan respon penerimaan yang ditunjukkan dengan antusias dan rasa semangat siswa kelas $3 \mathrm{~A}$ serta respon penolakan yang ditunjukkan dengan masih terdapat siswa yang malas dan tidak mengikuti apel penguatan pendidikan karakter.

Abstract

The purpose of this study was to describe the implanting of responsible attitudes of class $3 A$ students of SDN Tambakaji 01 by implementing morning assembly to strengthen the character education. This study used a descriptive qualitative method. Data collection used observation techniques, field notes, interviews, questionnaires, and documentation. Data analysis techniques were implemented to test validity which used triangulation of sources, triangulation of techniques, and triangulation of time. Then perform the confirmability test. The results of this study indicated that: (1) the morning roll call to strengthening the character education had three activities which serve as a means of inculcating a responsible attitude of habituation, role models, and strengthening; (2) Obstacles to the implementation of the strengthening of character education include unfavorable weather factors, the class was located far from the field, lack of guidance and direction of class $3 \mathrm{~A}$ teacher and laziness of class $3 \mathrm{~A}$ students; (3) Class $3 A$ students gave an acceptance response which was shown with enthusiasm and a sense of enthusiasm of class $3 \mathrm{~A}$ students as well as a rejection response indicated by there are students who were lazy and did not participate in morning roll call of strengthening the character education.
\end{abstract}

(C) 2020 Universitas Negeri Semarang

\footnotetext{
Alamat korespondensi:

Jalan Cermai RT 09/RW 02 Kedondong, Demak.

E-mail: evatriyani123@gmail.com.
}

ISSN 2252-6366 


\section{PENDAHULUAN}

Permasalahan karakter siswa sekolah dasar di Indonesia menjadi sorotan utama bahwasannya pendidikan yang hakekatnya mencetak generasi unggul justru menjadi ancaman. Berdasarkan International Civic and Citizenship Education Study (ICCS) menyampaikan tingkat pengetahuan sikap nasionalis di Indonesia menduduki posisi ke 36 dari 38 negara. Hal tersebut memicu perlunya upaya untuk membentuk karakter unggul generasi bangsa (Ahmadi, 2017:130). Berkowitz \& Bier (dalam Pattaro, 2016:7) menerangkan bahwa pendidikan karakter merupakan sebuah peran untuk mengembangkan sikap disiplin dan tanggung jawab.

Saat ini pemerintah mencanangkan adanya program Penguatan Pendidikan Karakter yang dituangkan dalam Peraturan Presiden (Perpres) Nomor: 87 Tahun 2017 tentang Penguatan Pendidikan Karakter yang bertujuan untuk memperkokoh karakter sebagai bentuk harmonisasi olahhati, olahrasa, olahraga, dan olahpikir dengan melibatkan masyarakat sebagai bagian dari Gerakan Nasional Revolusi Mental (GNRM) serta memaksimalkan 18 nilai karakter siswa.

Permasalahan yang terjadi di SDN Tambakaji 01 Kota Semarang adalah kurang otpimalnya program penguatan pendidikan karakter, siswa kurang mematuhi aturan yang diberlakukan di kelas maupun di sekolah, terdapat siswa yang membuang sampah tidak pada tempatnya, siswa tidak mengerjakan tugas tepat waktu, siswa kurang memiliki kesadaran untuk mengakui kesalahan. Permasalahan-permasalahan tersebut masih dapat diperbaiki Melalui kegiatan positif seperti pembiasaan apel penguatan pendidikan karakter (apel PPK) di sekolah guna menanamkan sikap tanggung jawab.

Darmiatun (2013: 142) menjelaskan bahwa sikap tanggung jawab merupakan tingkah laku seseorang dalam menghadapi situasi sekitar guna melaksanakan tugas dan kewajibannya baik untuk diri sendiri, lingkungan, masyarakat, negara dan Tuhan Yang Maha Esa. Selain itu, Arfiah (2017:170) juga menjelaskan bahwa karakter tanggung jawab merupakan kemampuan dari dalam diri manusia dalam mengambil keputusan untuk melaksanakan tugas dan kewajibannya. Widyaningtyas (2018: 113) juga menjelaskan bahwa sikap tanggung jawab merupakan keharusan individu untuk menjalankan komitmen secara penuh.

Adanya pembiasaan positif akan memberikan dampak terhadap sikap tanggung jawab siswa, seperti yang dijelaskan oleh Mislia (2016: 130) mengemukakan bahwa upaya pembentukan karakter tanggung jawab tidak hanya diintegrasikan kedalam pembelajaran semata, namun diimplementasikan kedalam pembiasaan hidup guna memuspuk nilai-nilai yang baik sehingga sikap siswa akan terbentuk. Hal tersebut selaras dengan penelitian oleh Anggraini (2017) yang berjudul "Implementasi Pendidikan Karakter Melalui Budaya Sekolah di $S D N$ Kotagede 3 Yogyakarta Tahun Ajaran 2016/2017". Memperoleh hasil bahwa terdapat hubungan antara pelaksanaan kegiatan berbasis pendidikan karakter terhadap karakter tanggung jawab anak terlebih melalui kegiatan pembiasaan. Selanjutnya penelitian oleh Nuriyatun tahun 2016 yang berjudul "Implementasi Pendidikan Karakter Disiplin dan Tanggung Jawab di SD Negeri 1 Bantul" yang didapatkan hasil bahwa implementasi pendidikan karakter melalui budaya sekolah mampu meningkatkan sikap sosial siswa terlebih pada sikap disiplin dan tanggung jawab.

Berdasarkan latar belakang tersebut, maka perlu diadakan pengkajian terhadap penanaman sikap tanggung jawab melalui apel penguatan pendidikan karakter siswa kelas $3 \mathrm{~A}$ SDN Tambakkaji 01 Kota Semarang. Tujuan penelitian ini adalah untuk (1) mendeskripsikan bentuk penanaman sikap tanggung jawab siswa kelas $3 \mathrm{~A}$ melalui apel penguatan pendidikan karakter (apel PPK); (2) mengidentifikasi hambatan dalam pelaksanaan apel penguatan pendidikan karakter (apel PPK); (3) mendeskripsikan respon siswa kelas 3A terhadap pelaksanaan apel penguatan pendidikan karakter (apel PPK).

\section{METODE PENELITIAN}

Penelitian ini menggunakan pendekatan kualitatif deskriptif untuk mengkaji penanaman sikap tanggung jawab melalui pembiasaan apel penguatan pendidikan karakter siswa kelas 3A SDN Tambakaji 01 Kota Semarang. Menurut Sugiyono (2016:15) metode penelitian kualitatif merupakan metode penelitian yang menekankan pada kondisi obyek alamiah dimana peneliti sebagai instrumen kunci serta teknik pengumpulan data melalui triangulasi dan lebih menekankan pada hasil yang bermakna dari pada generalisasi. Peneliti terjun langsung dalam lapangan mencari data-data yang diperlukannya. Peneliti memperoleh data dengan mencatat semua peristiwa, kata-kata, tindakan, dan mendokumentasikannya dalam foto atau rekaman.

Subjek penelitian ini adalah 30 siswa kelas 3A SDN Tambakaji 01 Kota Semarang, guru kelas 3A, kepala sekolah. Sementara itu, objek dalam penelitian ini adalah sikap tanggung jawab, apel penguatan pendidikan karakter (apel PPK). Teknik pengumpulan 
data menggunakan metode observasi, catatan lapangan, wawancara, angket, dan dokumentasi. Observasi dilakukan selama 6 kali untuk memperoleh data yang jenuh dari subjek penelitian. Digunakan uji kredibilitas dan uji konfirmabilitas untuk menguji keabsahan data. Untuk menjamin validitas data yang telah diperoleh digunakan teknik triangulasi. Triangulasi yang digunakan adalah triangulasi teknik, triangulasi sumber, dan triangulasi waktu serta menggunakan bahan referensi dan member check.

Analisis data dilakukan sebanyak dua kali yaitu analisis sebelum di lapangan dan analisis selama di lapangan. Analisis sebelum di lapangan dilakukan pada penelitian awal untuk menentukan fokus penelitian. Kemudian data selama di lapangan dianalisis menggunakan teknik deskripsi analisis kualitatif, dimana peneliti akan menggambarkan keadaan atau fenomena yang diperoleh dan kemudian akan dianalisis dalam bentuk kata- kata untuk memperoleh kesimpulan. Dalam penelitian ini digunakan analisis data kualitatif dari Miles and Huberman yang terdiri dari empat tahapan yaitu pengumpulan data, reduksi data, penyajian data, dan menarik kesimpulan atau verifikasi (Ulfatin:2015).

\section{HASIL DAN PEMBAHASAN}

Pendidikan nasional diarahkan kepada penguatan pendidikan karakter. Hal ini dimaksudkan agar ekosistem dalam dunia pendidikan mampu mengintegrasikan kebiasaan- kebiasaan positif sehingga dapat mengembangkan bakat, potensi dan keterampilan siswa (Kristiantari, 2018:135). Selaras dengan penelitian yang dilakukan oleh Khotimah (2019: 29) bahwa melalui pembudayaan positif di sekolah mampu mempengaruhi karakter siswa sehingga terbentuk sikap dan perilaku yang positif pula. Apel PPK memberikan pengaruh terhadap sikap tanggung jawab siswa kelas 3A SDN Tambakaji 01.

\section{Pelaksanaan Apel Penguatan Pendidikan}

Karakter (Apel PPK) sebagai Bentuk Penanaman Sikap Tanggung Jawab Siswa

\section{Kelas 3A SDN Tambakaji 01}

Perdana (2018: 187) berpendapat bahwa selain untuk mengembangkan pengetahuan, pendidikan karakter bertujuan untuk membentuk pribadi seseorang, kemandirian, keterampilan sosial, serta karakter seseorang. Bentuk penanaman sikap tanggung jawab yang terintegrasi dalam apel penguatan pendidikan karakter (apel PPK) di SDN Tambakaji 01 memiliki beberapa bagian berupa kegiatan.
Adapun bentuk penanaman sikap tanggung jawab tersebut sebagai berikut:

1. Pembiasaan

Pembiasaan ini adalah bagian dimana siswa kelas 3A melakukan kegiatan rutin dan terstruktur dalam pelaksanaan apel penguatan pendidikan karakter (apel PPK) yakni mulai dari pukul 07.00 WIB bel sekolah berbunyi, siswa diharuskan menuju ke lapangan dengan mengambil papan nama kelas yang sudah disediakan di samping kantor guru. Selanjutnya, sebelum apel penguatan pendidikan karakter (apel PPK) dimulai ketua kelas harus membariskan seluruh siswa kelas $3 \mathrm{~A}$ begitupun dengan seluruh siswa kelas $3 \mathrm{~A}$ yakni harus berbaris membentuk dua barisan dengan formasi siswa laki-laki berada di barisan kanan yang disesuaikan berdasarkan tinggi badan rendah ke tinggi. Selain itu, pembiasaan lain yakni adanya keharusan siswa untuk menirukan janji siswa, tepuk PPK, salam PPK, yel-yel SDN Tambakaji 01, mars PPK, serta siswa wajib menghafalkan lagu Indonesia Raya 3 Stanza.

Pembiasaan lain yang diterapkan kepada siswa yakni ketika apel penguatan pendidikan karakter (apel PPK) selesai, siswa menuju kelas masing-masing dengan formasi masih dalam barisan dan berjalan seperti langkah tentara. Kegiatan tersebut diiringi dengan pemutaran lagu-lagu perjuangan oleh guru. Selanjutnya, pembiasaan yang juga diterapkan guna menanamkan sikap tanggung jawab siswa kelas 3A yaitu adanya kegiatan tambahan berupa dinamika kelompok yang dilaksanakan setelah apel PPK hari rabu dan kamis. Kegiatan tersebut bertujuan agar siswa memiliki tugas dan kewajiban untuk saling peduli terhadap teman bukan hanya teman satu kelas saja namun juga teman satu sekolah. 2. Pemberian Teladan

Apel penguatan pendidikan karakter (apel PPK) tidak hanya dibebankan kepada siswa SDN Tambakaji 01, akan tetapi semua warga sekolah juga terlibat. Hal tersebut dimaksudkan agar guru juga memiliki peran dalam membentuk sikap tanggung jawab siswa. Adanya pelaksanaan apel penguatan pendidikan karakter (apel PPK) menjadi sarana guru kelas dalam memberikan arahan dan bimbingan berupa himbauan dan pemberian sanksi apabila siswa tidak menaati peraturan selama pelaksanaan apel penguatan pendidikan karakter (apel PPK). Dalam pelaksanaan apel penguatan pendidikan karakter (apel PPK) guru ikut serta berbaris dan melakukan hal yang sama seperti yang dilakukan siswa seperti ketika harus menyanyikan lagu Indonesia Raya 3 stanza, menyanyikan mars PPK, menyanyikan yel-yel SDN Tambakaji 01. 


\section{Penguatan}

Darmiatun (2013: 103) menjelaskan bahwa penguatan harus dilakukan secara terus menerus agar tujuan dapat tercapai. Hal tersebut sudah diterapkan oleh guru kelas $3 \mathrm{~A}$ guna menanamkan sikap tanggung jawab siswa kelas $3 \mathrm{~A}$ melalui pemberian wawasan tentang pendidikan yang diterapkan di negara lain. Sehingga siswa memiliki gambaran tentang pendidikan yang baik. Penguatan lain juga diterapkan dalam bentuk pemberian arahan dan motivasi oleh perwakilan guru disela-sela dinamika kelompok apel penguatan pendidikan karakter (apel PPK).

Pelaksanaan apel penguatan pendidikan karakter (apel PPK) sudah berjalan dan menjadi rutinitas di SDN Tambakaji 01, sehingga hal tersebut tidak lagi menjadi suatu beban bagi siswa maupun warga sekolah. Adanya kegiatan tersebut memberikan dampak yang baik terhadap sikap tanggung jawab siswa kelas 3A tidak hanya secara pribadi namun juga dalam berinteraksi.Hal tersebut selaras dengan hasil penelitian Nuriyatun tahun 2016 yang berjudul "Implementasi Pendidikan Karakter Disiplin dan Tanggung Jawab di SD Negeri 1 Bantul" yang menyatakan bahwa sikap tanggung jawab siswa dapat dibentuk melalui budaya sekolah dan pengintegrasian nilai-nilai karakter. Peneliti memperoleh data bahwa siswa tidak pernah merasa terbebani adanya apel PPK, justru hal tersebut menjadi sarana baik untuk memupuk tanggung jawab individu siswa. Kemudian, siswa juga menyampaikan dengan adanya pembudayaan sikap positif yang berikan oleh guru kelas $3 \mathrm{~A}$ sebelum apel PPK, mampu menjadi contoh bagi siswa sehingga siswa memiliki arah untuk mentaati peraturan kelas dan sekolah. Adanya apel PPK efektif memupuk sikap tanggung jawab siswa kelas 3A dalam hal tingkah laku terhadap guru kelas salah satunya yakni siswa selalu ijin apabila hendak ke kamar mandi.

Apel PPK tidak hanya memberikan pengaruh terhadap sikap tanggung jawab secara pibadi siswa kelas $3 \mathrm{~A}$ saja, namun juga menanamkan sikap tanggung jawab terhadap lingkungan sekitar yakni adanya program memungut sampah yang diterapkan ketika selesai apel PPK. Sikap tanggung jawab akan terbentuk dengan baik apabila dilakukan pembudayaan positif secara terus-menerus .Maka diperlukan langkah yang panjang agar karakter yang terebentuk kuat. (Masruroh, 2019: 16).

\section{Hambatan dalam Pelaksanaan Apel Penguatan Pendidikan Karakter (Apel PPK) guna Menanamkan Sikap Tanggung Jawab Siswa Kelas 3A SDN Tambakaji 01}

Pendidikan hingga saat ini masih menjadi sarana yang tepat dalam membentuk dan mengembangkan sikap atau karakter siswa, tidak hanya dalam kecerdasan akademis namun juga keterampilan berinteraksi. (Azzet, 2014: 9). Zuriah dalam (Handayani, 2018: 117) mengatakan bahwa era global mempengaruhi nilai moral siswa, oleh sebab itu perlu adanya upaya penanaman nilai-nilai karakter agar terbentuk sikap yang baik. Akan tetapi, dalam setiap pelaksanaan kegiatan tidak terlelpas dengan kendala maupun hambatan. Adapun hambatan dalam pelaksanaan apel penguatan pendidikan karakter (apel PPK) antara lain:

1. Hambatan Bagi Sekolah

Pelaksanaan apel penguatan pendidikan karakter (apel PPK) tidak selalu berjalan dengan baik. Adakalanya terjadi suatu hal yang mengakibatkan apel harus ditunda atau bahkan tidak dilaksanakan. Berdasarkan wawancara bersama bapak Kuswardono, S.Pd., menjelaskan bahwa hambatan yang sering dihadapi pihak sekolah adalah ketika cuaca tidak mendukung seperti hujan. Selain itu juga ketika terdapat kegiatan-kegiatan sekolah yang tidak memungkinkan untuk melaksanakan apel penguatan pendidikan karakter (apel PPK).

2. Hambatan Bagi Guru

Hambatan yang sering dialami oleh guru kelas berkaitan dengan pelaksanaan apel penguatan karakter (apel PPK) yaitu ketika terdapat siswa yang malas-malasan melaksanakan apel PPK. Berdasarkan hasil wawancara dengan bapak Agus Budiyanto selaku guru kelas $3 \mathrm{~A}$, didapatkan hasil bahwa kendala dan hambatan pada saat apel berlangsung adalah masih terdapat siswa yang berbicara dengan teman. Selain itu juga terkendala pada pemberian arahan terhadap siswa kelas 3A. Akan tetapi hal tersebut mampu ditangani oleh guru kelas 3A dengan memberikan pengetahuan pentingnya memiliki sikap tanggung jawab melalui apel PPK.

3. Hambatan Bagi Siswa

Apel penguatan pendidikan karakter (apel PPK) dilaksanakan di lapangan utama SDN Tambakaji 01. Sementara ruang kelas 3A berada di lantai dua gedung sekolah. Berdasarkan hasil observasi, catatan lapangan, serta wawancara terhadap sekelompok siswa kelas 3A didapatkn hasil bahwa kendala dan hambatan yang dialami oleh siswa kelas $3 \mathrm{~A}$ terhadap pelaksanaan apel penguatan pendidikan karakter (apel PPK) antara lain disebabkan karena letak ruang kelas yang jauh dari lapangan sehingga siswa kelas $3 \mathrm{~A}$ harus naik turun tangga dan terburu-buru menuju ke lapangan. 
Respon Siswa Kelas 3A SDN Tambakaji 01 terhadap Pembiasaan Apel Penguatan Pendidikan Karakter (Apel PPK).

Zarkasi (2018: 6) menjelaskan bahwa pendidikan karakter memiliki kedudukan lebih tinggi dibandingkan dengan pendidikan moral, karena pendidikan karakter berkaitan dengan tingkah laku yang diterapkan dalam kehidupan sehari-hari dan berkelanjutan. Salah satu bentuk penanaman sikap di sekolah yaitu melalui pengintegrasian pendidikan karakter kedalam mata pelajaran, pembinaan kesiswaan, serta budaya sekolah. Pembiasaan apel penguatan pendidikan karakter (apel PPK) menerima respon dari siswa tidak hanya respon penerimaan akan tetapi juga respon penolakan.

Berikut penjelasannya:

1. Respon Penerimaan

Pembudayaan positif yang diterapkan secara baik akan memberikan dampak signifikan terhadap objek yang menjadi sasaran. Apel PPK dirasa mampu merangsang siswa untuk mewujudkan kebiasaan baik melalui rutinitas apel PPK. Lebih dari 50\% mengatakan sangat antusias dengan adanya apel PPK. Hal tersebut diungkapakan oleh salah satu siswa bernama RAGS bahwa apel PPK sangat seru karena mengajarkan banyak hal seperti ketertiban, tanggung jawab, kedisiplinan, bermain, mengenal banyak teman melalui dinaika kelompok. Selan itu siswa lain juga menyamapaikan bahwasannya melalui apel PPK siswa kelas 3A diajarkan cara menjadi seseorang yang peduli terhadap lingkungan sekitar serta bertanggung jawab atas tugas dan kewajiban sebagai siswa. Selanjutnya, siswa sudah tidak merasa terbebani adanya pelaksanaan apel PPK dikarenakan sudah menjadi rutinitas siswa. Sehingga guru kelas hanya memberikan sedikit arahan ketika beberapa siswa kurang tertib pada aturan.

\section{Respon Penolakan}

Pelaksanaan penguatan pendidikan karakter tidak selamanya berhasil diterima dan diterapakan dalam diri siswa. Siswa kelas 3A SDN Tambakaji 01 masih terdapat beberapa siswa yang enggan untuk mengikuti apel PPK dengan alasan yang kurang tepat. Hal tersebut tidak lantas menjadikan siswa kelas 3A yang lain terpengaruh untuk melakukan hal yang sama. Selanjutnya, sebanyak 2 siswa terkadang membolos mengikuti apel PPK. Namun, hal tersebut tidak menjadi dominan dalam perilaku siswa khususnya sikap tanggung jawab siswa kelas 3A SDN Tambakaji 01.

\section{SIMPULAN}

Berdasarkan hasil penelitian dan pembahasan oleh peneliti, maka dapat ditarik simpulan sebagai berikut: (1) Pelaksanaan apel penguatan pendidikan karakter (apel PPK) memiliki tiga kegiatan yang dijadikan sebagai sarana penanaman sikap tanggung jawab siswa kelas 3A SDN Tambakaji 01 yakni pembiasaan, pemberian teladan, serta penguatan. Kegiatan tersebut terlaksana dengan baik dan mampu membentuk sikap tanggung jawab siswa kelas 3A; (2) Pelaksanaan apel penguatan pendidikan karakter (apel PPK) terdapat hambatan bagi sekolah, bagi guru, dan bagi siswa. Hambatan yang dihadapi sekolah yaitu ketika cuaca tidak mendukung untuk melaksanakan apel PPK seperti hujan. Selanjutnya hambatan bagi guru yakni ketika terdapat siswa yang bermalasmalasan sehingga guru harus memberikan arahan dan bimbingan. Kemudian hambatan yang dihadapi siswa kelas 3A adalah letak ruang kelas yang berada di lantai dua menyebabkan siswa harus terburu- buru menuju ke lapangan; (3) Pelaksanaan apel penguatan pendidikan karakter (apel PPK) memunculkan respon penerimaan siswa kelas 3A SDN Tambakaji 01 yakni tingginya rasa semangat dan antusias siswa kelas 3A sehingga tidak merasa terbebani dengan adanya apel PPK. Selain itu, masih terdapat beberapa siswa yang memberikan respon penolakan, akan tetapi hal tersebut tidak mendominasi.

\section{UCAPAN TERIMAKASIH}

Ucapan terimakasih disampaikan kepada (1) Tuhan Yang Maha Esa; (2) Kedua orang tua yang selalu memberikan dukungan dan doa; (3) Drs. A. Busyairi, M.Ag., selaku dosen pembimbing yang telah memberikan bimbingan, petunjuk serta semangat untuk menyusun manuskrip; (4) Desi Wulandari, S.Pd., M.Pd. dan Dr. Ali Sunarso, M.Pd., selaku mitra bestari yang telah memberikan bimbingan dan masukkan untuk kesempurnaan manuskrip ini; (4) Arif Widagdo, S.Pd., M.Pd selaku dosen penyunting abstrak bahasa Inggris yang membantu menyempurnakan manuskrip ini.

\section{DAFTAR PUSTAKA}

Ahmadi, Farid dkk. 2017. Pengembangan Media Edukasi "Multimedia Indonesian Culture" (MIC) sebagai Penguatan Pendidikan Karakter Siswa Sekolah Dasar. Jurnal Penelitian Pendidikan, 34(2), 128.

Anggraini, Melani dkk. (2017). Implementasi Pendidikan Karakter Melalui Budaya Sekolah di SDN Kotagede 3 Yogyakarta Tahun Ajaran 2016/2017. Jurnal Pendidikan Ke-SD-an, 3(3), 157. 
Arfiah, Sri \& Agus P. (2017). Pembelajaran Kepramukaan dalam Penguatan Karakter Kemandirian dan Tanggung Jawab dalam Upaya Mempersiapkan Mahasiswa PPKn sebagai Pembina Ekstrakurikuler di Sekolah. The $6^{\text {th }}$ University Research Colloquium 2017. 27(2), 170.

Azzet, Akhmad M. 2014. Urgensi Pendidikan Karakter di Indonesia.Yogjakarta: ArRuzz Media.

Darmiatun, S. 2013. Implementasi Pendidikan Karakter di Sekolah. Yogyakarta: Gava Media.

Handayani, Trisna dkk. (2018). Student Character Building Reconstruction Junior High School in District Galesong Takalar Based Values National Culture. Journal of Educational Social Studies, 7(2), 117.

Khotimah, D.N. (2019). Implementasi Program Penguatan Pendidikan Karakter (PPK) Melalui Kegiatan 5S di Sekolah Dasar. Inopendas Jurnal Ilmiah Kependidikan, 2(1),29- 31.

Kristiantari, Rini.(2018). Penguatan

Pendidikan Karater Berbasis Kelas bagi Guru- Guru Sekolah Dasar Gugus Kompiang Sujana di Kota Denpasar. Jurnal Pengabdian Kepada Masyarakat, 1(2), 135.

Masruroh, Aini dkk. (2019). Membentuk Karakter Dan Disiplin Siswa Melalui Pembinaan Apel Pagi. Buletin Pengembangan Perangkat Pembelajaran, 1(1), 16.

Mislia, dkk. (2016). The Implementation of Character Education throught Scout
Activities. International Education Studies, 9(6), 130.

Nuriyatun, Puji D. (2016). Implementasi Pendidikan Karakter Disiplin dan Tanggung Jawab di SD Negeri 1 Bantul. Jurnal Pendidikan Guru Sekolah.

Pattaro, Chiara. (2016). Character Education: Themes and Researches. An Academi Literature Review. Italian Journal of Sociology of Education, 8(1), 7.

Perdana, Novrian S. (2018). Implementasi Peranan Ekosistem Pendidikan dalam Penguatan Pendidikan Karakter Peserta Didik. Jurnal Refleksi Edukatika, 8(2), 187-190.

Sugiyono. 2016. Metode Penelitian Pendidikan. Bandung: Alfabeta.

Ulfatin, Nurul. 2015. Metode Penelitian Kualiatif Di Bidang Pendidikan: Teoridan Aplikasinya. Malang: Media Nusa Creative

Widyaningtyas, Harini dkk. (2018). Developing Students Responbility Throught Numbered Head Togheter Model In Social Sciene Learning At Elementry School. International Journal of Indonesian Education and Teaching, 2(2), 113.

Zarkasi, Taqiudin \& Al K. (2018). Penguatan Pendidikan Karakter di Madrasah (Perpres No 68 Tahun 2017). Jurnal Al-Muta'aliyah STAI Darul Kamal NW Kembang Kerang, $\quad 1(3), \quad 6$ 